\title{
Nas vias de interromper ou não a gestação: vivências de gestantes de fetos com anencefalia
}

\author{
On the way to interrupting the gestation or not: experiences of \\ pregnant women with anencephalic fetuses
}

Iulia Bicu Fernandes (https://orcid.org/0000-0002-2857-2938) ${ }^{1}$

Rozania Bicego Xavier (https://orcid.org/0000-0003-3435-8038) ${ }^{2}$

Paulo Alexandre de Souza São Bento (https://orcid.org/0000-0002-1598-3340) ${ }^{3}$

Andreza Rodrigues (https://orcid.org/0000-0002-1873-5828) ${ }^{4}$
${ }^{1}$ Hospital Municipal de Petrópolis Alcides Carneiro. R. Vigário Correas 1345, Correas. 25720-320 Petrópolis RJ Brasil. iulia.bicu.86@gmail.com ${ }^{2}$ Departamento de Ginecologia e Obstetrícia. IFF, Fiocruz. Rio de Janeiro RJ Brasil.

${ }^{3}$ Núcleo Interno de Regulação, IFF, Fiocruz. Rio de Janeiro RJ Brasil. ${ }^{4}$ Escola de Enfermagem Anna Nery, Universidade Federal do Rio de Janeiro. Rio de Janeiro RJ Brasil.

\begin{abstract}
Anencephaly is a malformation characterized by the total or partial absence of the brain, and Brazil records the fourth largest number of births of anencephalic fetuses in the world. Fetal anencephaly is associated with a more significant number of maternal complications. As of 2012, women with anencephalic gestation were empowered with the right to carry the pregnancy to term or terminate it, if they so desired, without any judicial authorization. Objectives: to understand the experiences of women with fetal anencephaly and to identify the determinant factors for interrupting the gestation or not. This is a qualitative study using the Life Narratives method with 12 women over 18 years old diagnosed with an anencephalic fetus, who interrupted gestation or delivery in a public maternity hospital in Rio de Janeiro. Data were collected between June and November 2016, and the process was finalized when the narrative patterns reached progressive saturation from the recurrences. The statements that emerged following floating and in-depth reading were articulated in Narrative Nuclei, and data comparative and comprehensive analysis was performed. The reports brought to light the intense experiences of these women, as well as the weaknesses existing concerning care and the pregnancy termination issue.
\end{abstract}

Key words Anencephaly, Legal abortion, Abortion candidates, Women's health, Public health
Resumo A anencefalia é uma malformação caracterizada pela ausência total ou parcial do encéfalo e o Brasil é o quarto colocado em número de nascimentos de fetos anencéfalos no mundo. Existe associação entre anencefalia fetal e maior número de complicações maternas. A partir de 2012 a mulher com gestação de anencéfalo poderá manter ou interromper a gestação, se assim o desejar, sem necessidade de autorização judicial. Objetivos: compreender as vivências das mulheres de fetos com anencefalia e identificar os fatores determinantes para a escolha de interromper ou não interromper a gestação. Estudo qualitativo e método das narrativas de vida, com 12 mulheres, maiores de 18 anos e com diagnóstico de feto anencéfalo, que realizaram a interrupção da gestação ou o parto em uma maternidade pública do Rio de Janeiro. A coleta dos dados foi entre junho e novembro de 2016 e encerrada quando os padrões narrativos alcançaram a saturação progressiva, a partir das recorrências. Os enunciados emergidos após leitura flutuante e aprofundada foram articulados em Núcleos Narrativos e realizada análise comparativa e compreensiva dos dados. Os relatos trouxeram à tona as vivências intensas dessas mulheres, como também as fragilidades existentes em relação ao cuidado e a problemática da interrupção da gestação.

Palavras-chave Anencefalia, Aborto legal, Aspirantes a aborto, Saúde da mulher, Saúde pública 


\section{Introdução}

A anencefalia é uma malformação caracterizada pela ausência total ou parcial do encéfalo, sendo esta última a forma mais comum; ela é incompatível com a vida extrauterina, sobrevivendo o feto somente por horas ou dias após o parto ${ }^{1-3}$. De acordo com dados da Organização Mundial da Saúde, Brasil é o quarto colocado no número de nascimentos de fetos anencéfalos (1/1600 nascidos vivos), ficando atrás somente do México, Chile e Paraguai ${ }^{2,4}$. Das gestações que são levadas a termo, aproximadamente $75 \%$ dos anencéfalos são natimortos e o restante morre no período neonatal ${ }^{4,5}$. Deparar-se com o diagnóstico de um filho incompatível com a vida extrauterina leva os pais a enfrentarem grande sofrimento e intensas vivências emocionais ${ }^{6}$, além de complicações de saúde na gestante, como hipertensão arterial, gravidez prolongada, polidramnia, entre outros ${ }^{4,5}$.

Apesar do risco de complicações físicas e emocionais, somente em abril de 2012 o Supremo Tribunal Federal decidiu pela descriminalização da interrupção da gestação de fetos anencéfalos. Estabeleceu-se o direito pela interrupção terapêutica da gestação sem precisar de autorização judicial prévia ou pela manutenção desta, se a mulher assim o desejar ${ }^{5,7}$. A prática da interrupção da gestação em casos de anencefalia não pode ser configurada como abortamento, pois se trata de interrupção terapêutica da gestação ou antecipação terapêutica do parto, pelos riscos aumentados à saúde das gestantes e fetos sem possibilidade de vida após o nascimento ${ }^{3,5}$.

Estudos sobre anencefalia e aborto legal referente à realidade brasileira nos últimos 15 anos apontou somente para três estudos ${ }^{4,6,8}$ que discutiram especificamente os aspectos emocionais da gestação de feto anencéfalo. Assim, são objetivos deste artigo: compreender as vivências das mulheres de fetos com anencefalia e identificar os fatores determinantes para a escolha de interromper ou não interromper a gestação.

\section{Métodos}

O método de estudo foi das Narrativas de Vida nas proposições de Bertaux ${ }^{9}$, com participação de 12 mulheres maiores de 18 anos e com diagnóstico de feto anencéfalo, que realizaram a interrupção da gestação ou o parto em uma maternidade pública na cidade do Rio de Janeiro. A coleta de dados se deu após a apreciação e aprovação pelo
Comité de Ética em Pesquisa da maternidade, respeitando as normas da Resolução 466/12 ${ }^{10}$. A entrevista ocorreu em local e horário de disponibilidade das participantes, após a assinatura do Termo de Consentimento Livre e Esclarecido, no período entre junho e novembro de 2016. Uma única pergunta disparadora foi realizada: "Você pode me contar como foram as suas gestações?". Demais inferencias foram feitas respeitando o que era dito pela participante. As entrevistas foram realizadas com um intervalo de, no mínimo, um ano após o parto referente ao bebê anencéfalo, permitindo à entrevistada refletir acerca da sua vivência, buscando através desta estratégia, minimizar desconfortos pelo processo de ressignificação da história vivida. Os padrões narrativos alcançaram a saturação progressiva na quinta entrevista, a partir das recorrências e a coleta dos dados foi encerrada na décima segunda entrevista, permitindo a pesquisa de caso negativo, ${ }^{9,1}$. Após as trascrições e leituras das entrevistas, os enunciados emergidos foram articulados em dois Núcleos Narrativos, de modo a possibilitar uma análise compreensiva e comparativa à luz de Bertaux'. Foi respeitado o anonimato e cada entrevista foi identificada utilizando a letra $\mathrm{E}$ (de entrevista) seguida por sistema alfanumérico de 1 a 12.

\section{Resultados e discussão}

As doze mulheres entrevistadas encontravam-se em idade reprodutiva, na faixa etária entre 23 e 42 anos. A maioria declarou ter um filho vivo, com variação de zero a três filhos por participante. Nove identificaram-se como casadas ou em união estável e as outras se declararam solteiras. Dez possuíam ensino médio e superior e nove relataram estar formalmente empregadas. A renda familiar variou entre zero e 11 salários mínimos.

Em relação à gestação do bebê anencéfalo, em metade dos casos se tratou da primeira gestação e 75\% das mulheres declararam ter se tratado de gestação planejada. Em relação à entrada no Judiciário a fim de obter a autorização para a interrupção terapêutica da gestação, quatro das mulheres recorreram, apesar de em oito casos, existir jurisdição para o procedimento.

Algumas mulheres tiveram que sepultar seus filhos, pois se tratava de fetos com idade gestacional superior a seis meses. Se a interrupção ocorrer com idade gestacional inferior a 20 semanas de gestação, o feto pesar menos de 500 gramas e estatura menor que 25 centímetros, a declara- 
ção de óbito é facultativa, conforme Legislação vigente, sendo emitida quando há o desejo familiar de sepultamento. Caso contrário, o feto ficará no hospital, sendo posteriormente incinerado ou entregue à adequada coleta hospitalar ${ }^{12}$.

\section{Do ventre pleno ao colo vazio: um trânsito entre a expectativa e realidade}

Um primeiro eixo a ser considerado nesta análise é que a concretização da maternidade biológica permanece, para algumas mulheres, como um forte desejo e que se confunde com os papéis de gênero socialmente construídos. É sabido que na contemporaneidade - considerando os senões que esta classificação evoca - as mulheres têm conquistado diversos espaços do âmbito público, buscando realização profissional, inserção no mercado de trabalho, vocalização política e autonomia econômica.

As mulheres, mesmo sendo maioria numérica no Brasil (51\% da população), ainda recebem $30 \%$ menos do que homens na realização dos mesmos trabalhos, possuem menos cargos de liderança e, não somente contribuem com a renda de suas famílias, mas são arrimo de muitas ${ }^{13}$. Para uma parte destas mulheres um dos seus projetos pessoais é o desejo da maternidade. Mais do que isso, a sociedade ainda demanda, fortemente, esta questão enquanto um papel social da mulher"

As noções de vocação e obrigatoriedade em gestar e parir um filho biológico possuem uma historicidade que confere aspectos identitários atrelados à mulher, que reúne representações capazes de estabelecer nexos entre 'ser mulher' e 'ser mãe'. Cumprir este papel social, que possui raízes socioculturais patriarcalistas e utilitaristas, é como atender a uma ampla tradição cultural que é, diretamente ou indiretamente, imposta às mulheres ${ }^{4}$.

Neste caminho, uma pergunta é estruturante para este núcleo narrativo, isto é: quais as expectativas sobre a gestação compartilhadas pelas mulheres? A enfática afirmativa de E2 quando soube do diagnóstico da gravidez - "a gente ficou super feliz" - representa de maneira índex as expectativas das participantes deste estudo e seus parceiros, pois grande parte das gestações era desejada pelos casais e, nestes casos, a gravidez foi vivida com alegria e realização pessoal. Apenas no depoimento de E3, mãe de três filhos, encontrou-se traços de insegurança devido a uma situação financeira difícil, ao mesmo tempo em que se tratava de uma gestação não planejada. Mesmo assim, a participante compartilhou do mes- mo sentimento de alegria quando do diagnóstico de sua gestação.

A valoração da maternidade desde os idos do que se considera antiguidade leva muitas mulheres a depositarem um significado pessoal e muito importante em gerar um filho. A gravidez pode representar a confirmação da sua feminilidade e posição de aparente prestígio social ${ }^{14}$. Há também um conjunto de sonhos, esperanças e expectativas que as mulheres depositam na futura gestação, idealizando e imaginando o 'ser' que está em seu útero, sendo a mulher e muitas vezes o cônjuge envolvidos por sentimentos de realização pessoal e a idealização de uma criança perfeita $^{15,16}$. Em situações de vulnerabilidade, como no caso supracitado de E3, a literatura aponta que as mães solteiras possuem problemas com baixa renda em decorrência de oferta de emprego deficiente, com a falta de apoio do pai, dos escassos benefícios públicos, além de terem maior necessidade de redes de apoio ${ }^{17}$.

Assim, a realidade idílica da maternidade enquanto um atributo das mulheres, juntamente com as elevadas expectativas das participantes deste estudo com suas gravidezes, impuseram outras reflexões. Afinal, o que a gravidez de um feto com anencefalia apresenta de realidade concreta a estas mulheres? Se por um lado o diagnóstico da gravidez trouxe alegria, o diagnóstico da anencefalia trouxe uma gama de sentimentos negativos. Expectativas foram colocadas à prova. Tais sentimentos negativos foram compartilhados pela mulher, cônjuge e família trazendo uma ruptura relacionada à idealização do bebê perfeito $^{15}$. A gestação se torna uma realidade de intenso sofrimento e angústia emocional devido à frustração de expectativas ${ }^{16}$. É o difícil trânsito entre as expectativas relacionadas a felicidade para a árdua realidade em deparar-se com um feto malformado - um duplo que foi vivido, de forma agudizada no diagnóstico, passando por decisões, pelo parto, pelo destino do bebê morto e no retorno ao lar.

A gravidez de um feto anencéfalo gerou nas mulheres e seus cônjuges reações que envolveram palavras, tais como relatadas nos depoimentos: choque; angústia; tristeza; sofrimento; desespero; pânico e desorientação. Uma palavra do vernáculo popular surgiu em quatro depoimentos e carrega a noção do sentimento destas mulheres, ou seja, elas verbalizaram que foi um baque descobrir que o bebê era malformado:

perdi o meu chão, eu tava sozinha [...] aí eu desabei, chorei, [...] foi dias assim terríveis [...] levei quase uma semana naquela situação - E12. 
Defronte às expectativas frustradas e sentimentos angustiantes, as mulheres narraram sobre outro sentimento que foi a culpa. A culpabilização diante do ocorrido se deu por uma autocobrança, assim como, na evidente relação com o homem, uma vez que ela "carrega o bebê" elevando o seu status de maior propensão em se considerar responsável pelo desfecho da gestação ${ }^{16}$. Nestes meandros, elas questionaram a situação inesperada em busca de explicações e justificativas, nem sempre obtidas com êxito ${ }^{18}$ :

"porque comigo? que que eu fiz de errado?" você se pergunta - E6.

Outra realidade foi desconhecer o que era anencefalia. Das mulheres entrevistadas, nove delas nunca tinham ouvido falar neste problema e o desconhecimento foi um fator que atrelou ao processo sentimentos de ansiedade e estresse. É preciso considerar que, diante deste tema delicado e pouco falado, os profissionais responsáveis em noticiar este diagnóstico a uma mulher devem exercitar aquilo que se chama de comunicação de notícias difíceis.

O exame radiológico é um procedimento técnico, lugar onde o diagnóstico da anencefalia é obtido. É preciso pontuar que o procedimento é realizado em um indivíduo que possui subjetividades que não podem ser desconsideradas e, neste sentido, é iminente que os profissionais tenham consciência, pois também possuem suas subjetividades, de que ao realizar o procedimento, estão diante de alguém que se apresenta com uma forte carga emocional. Afinal, em última instância, é precisamente este profissional que apresenta, pela primeira vez, a imagem do filho à sua mãe e está em jogo nesta cena clínica a informação relacionada a saúde, ou não, do bebê ${ }^{19}$.

Das participantes deste estudo, sete deram a luz fetos com idade gestacional superior a seis meses e, por conseguinte, os bebês tiveram que ser enterrados. Eis uns dos acmes da ruptura entre o imaginário e a realidade posta a estas mulheres - o sepultamento. O diagnóstico de um bebê com anencefalia impôs, de pronto, a vivência de um luto, no plano das ideias, paulatinamente experienciado até o momento do parto. Diante do bebê nascido e morto, o luto passa para o plano concreto - visível e palpável. Este movimento implicou em um processo de reajuste emocional por parte das mulheres, seus parceiros e família, de acordo com os recursos subjetivos disponíveis $^{18}$. As outras cinco participantes da pesquisa não precisaram viver a situação de sepultar o filho, mas passaram por outra, a de autorizar o estudo genético dos seus bebês.
Considerando que a sensação de frustração e perda não se encerra com o nascimento e destino dos bebês mortos, o retorno ao lar se caracterizou como o segmento da experiência vivida de uma realidade não esperada. As participantes do estudo também utilizaram palavras carregadas de intensidade sobre o assunto: tristeza; perda; dor; inaceitação; revolta; culpa e vazio. O trânsito entre o idealizado e a dura realidade da ausência do bebê foi presente independente do tempo de gestação em que a mesma foi interrompida ${ }^{18}$. Para muitos pais, o nascimento de um filho é um pórtico de esperança para o futuro. Estar diante de um filho com defeitos é interromper esta idealização, é deparar-se com um futuro imperfeito onde o luto é uma resposta em relação, não somente à perda de uma criança idealizada, mas também às expectativas malogradas ${ }^{20,21}$ :

a parte pra mim mais difícil foi a chegada em casa [...] você de cesárea [...] doía muito olhar pra marca e [...] não ter o neném - E5.

Uma das entrevistadas (E7) relatou ter sofrido de estresse pós-traumático após a interrupção por cesariana no término da gestação. Apesar da decisão de não antecipar o parto ter sido unânime entre o casal, a mulher teve o diagnóstico de estresse pós-traumático na volta para o trabalho e apontou que com o apoio incondicional do esposo e família, conseguiu superar a situação. Os sintomas de estresse pós-traumático podem ser verificados em mulheres que realizam a interrupção da gestação, principalmente, em idade gestacional mais avançada ${ }^{6}$.

Para E2, a perda de um bebê anencéfalo significou romper com o desejo de uma nova gestação - "não senti a vontade de ter outro filho, fiquei muito traumatizada". Para outras participantes, o desejo de engravidar falou mais alto, como foi o caso de três delas. Para duas entrevistadas, a experiência da perda anterior as levou a uma gestação vivida com medo e apreensão relacionados a gerar um bebê malformado. $\mathrm{O}$ trauma gerado pela perda anterior potencializa uma memória nada silenciosa, aquela que não quer tornar a vivenciar uma gestação frustrada, tampouco, o luto posterior ${ }^{18}$ :

Dessa minha gestação agora [...] toda ultra que eu vou bater eu vou com aquele desespero - E5.

Diante desta realidade, a presença do companheiro e demais familiares, que demonstrem preocupação e que providenciem apoio, tem um papel fundamental para contribuir com a recuperação do equilíbrio emocional necessário à mulher que sofreu a perda. A família pode cooperar no processo de luto e o suporte fornecido, sem 
dúvida, auxiliará o casal a elaborar a perda a partir do que se estabelece enquanto rede de apoio ${ }^{18}$.

A maioria das participantes deste estudo teve apoio do companheiro e/ou da mãe, um aspecto central para a vivência do problema, desde o diagnóstico até o retorno ao lar. Mas nem sempre esta realidade se apresentou para todas as mulheres como foram os casos de E3 que não teve nenhuma rede de suporte, $\mathrm{E} 4 \mathrm{sem}$ apoio do marido e E8 que buscou ajuda na figura do marido e da mãe, não obtendo em nenhum dos dois. Vale enfatizar que na presença de companheiros, mães e demais familiares, o profissional pode, além de acolher e orientar a mulher, fazer o mesmo com sua rede familiar explicando que o apoio é fundamental para a vivência deste momento de vida. Existem recursos pessoais e socioecológicos de enfrentamento no processo de gestar um bebê com malformação e aqueles que perpassam pelas crenças ideológicas e pelo relacionamento conjugal, assim como, as redes sociais ${ }^{22}$ :

a família muito do meu lado, minha mãe [...] meu esposo sempre perto - E10.

A importância da rede de apoio pode ser identificada também por sua ausência, através dos relatos das mulheres que declararam ter vivido um percurso solitário. Narrativas que apontam para ausência de suporte do companheiro, família e pessoas próximas, assumidos enquanto entraves para atravessar a situação:

eu sempre fui sozinha, meu marido nunca quis me acompanhar [...] Para mim assim, eu me senti sozinha, sozinha, sozinha - E8.

Não suficiente a ausência de suporte, a participante E6 revelou que sofreu perseguição por parte de um grupo de pessoas religiosas. Uma vez tendo manifestado o desejo de interromper a gestação e por ter recorrido ao judiciário foi acusada de ser uma assassina. Não ter uma rede de apoio é, para a mulher, viver uma experiência solitária e angustiante diante de uma gravidez de feto anencéfalo. Ser acusada de assassina por decidir interromper a gestação, além de ferir seu direito adquirido, é fazê-la passar por uma situação de violência, aquela perpetrada por pessoas que, a princípio, deveriam dar apoio e acolhimento, é ser julgada moralmente/espiritualmente por pessoas e instituições:

tava negócio de igreja me perturbando, chegou a ir na minha casa, [...] iam na minha porta, falar que eu era uma assassina, porque eu tava querendo tirar-E6.

Os julgamentos em questão possuem raízes na polemização da questão do aborto no Brasil, que a literatura levanta com frequência, mes- mo em casos de fetos gravemente acometidos. A oposição à interrupção da gravidez em casos de anencefalia é de fundo religioso ${ }^{23}$ e como a grande maioria da população brasileira se autodeclara religiosa, é possível presenciar tais comportamentos voltados à mulher que decide pela interrupção da gestação, uma negação de direitos.

Ante as expectativas compartilhadas pelas mulheres desta pesquisa versus a concretude compulsória da realidade vivida de um feto anencéfalo, este núcleo narrativo assenta que a ausência de rede de apoio e julgamentos diversos constituem uma violência contra as mulheres. Em contrapartida, a gestante precisa encontrar um ambiente seguro e acolhedor, um facilitador para que a mesma verbalize e reflita seus sentimentos, preocupações, significações, crenças e necessidades pessoais, sem medo de represálias. Ela deve ser respeitada, antes de tudo, evitando-se juízos de valor, independente de sua decisão, diminuindo assim possíveis sentimentos de culpa ${ }^{8}$.

Neste difícil trânsito das expectativas à realidade, com todas as vicissitudes presentes, um aspecto merece relevo, o da resiliência das mulheres. A maioria das participantes deste estudo manifestou ter se tratado de uma vivência que lhes trouxe um grande aprendizado. Elas conseguiram significar o acontecido, superar limites dantes inimagináveis, verbalizando um amadurecimento gerador de fortes transformações de sua vida, de seus companheiros e de suas famílias ${ }^{20}$ :

é uma experiência de vida... a gente começa a amadurecer sem querer - E11.

\section{O percurso empreendido pelas mulheres: decisões e cuidados}

Para a compreensão do percurso empreendido pelas mulheres é preciso, de imediato, situar onde e como se deu o diagnóstico do problema e a assistência prestada pelos profissionais, para depois compreender escolhas e decisões. Foi no espaço das consultas de pré-natal ou nos centros de ultrassonografia que as mulheres receberam a difícil notícia de que estavam vivendo uma gravidez de um bebê anencéfalo. As mulheres deste estudo relataram que os profissionais foram cuidadosos em noticiar o diagnóstico e esclarecer os pormenores que envolviam informações relacionadas ao total desconhecimento deste tipo de problema, das especificações técnicas sobre a doença e das possibilidades de escolha frente a esta situação, que envolvia o pensar, escolher e decidir por interromper ou não a gestação, uma vez que o desfecho já era sabido. 
Neste sentido, foi neste espaço relacional - a consulta pré-natal ou centro de ultrassonografia - que, por um lado, profissionais cuidaram destas mulheres seguindo os protocolos assistenciais, fornecendo esclarecimentos que incluíam os relacionados aos seus direitos e legislação vigente ${ }^{6}$ e noutra face, as mulheres e seus companheiros frente as suas subjetividades que influenciariam suas escolhas. Embora pareça, a princípio, uma decisão focal - a opção pela interrupção da gestação ou de levá-la a termo - as escolhas se mostraram complexas dada a pluralidade de situações que atravessam este processo. Cumpre pontuar também que, em se tratando de um espaço relacional, a relação profissional/mulheres e companheiros foi construída a partir das intersubjetividades envolvidas.

A equipe médica tem a responsabilidade de informar a gestante sobre a malformação e prognóstico letal, já que nenhuma abordagem terapêutica poderá trazer melhora. O médico deverá ainda expor a possibilidade de interromper a gestação, seja pelos meios legais, através do alvará de autorização, seja através de uma ultrassonografia com a assinatura de dois médicos. Não cabe a ele impor ou manifestar sua opinião e deve-se buscar imparcialidade nas informações fornecidas, tal como esclarecimentos completos sobre os procedimentos diagnósticos e terapêuticos ${ }^{6,8}$, fato revelado nas entrevistas:

"a decisão é de vocês", explicou todos os direitos legais que a gente teria [...] ela foi muito delicada, atenciosa e falou isso tudo segurando na mão, foi bem, bem, bem humana - E7.

Segundo literatura, a disponibilidade de informação e uma atenção especializada da rede de saúde são elementos essenciais para a gestante e sua família se reorganizarem diante desse diagnóstico e ajudarem no enfrentamento e manejo da situação ${ }^{16}$.

O cuidado de qualidade oferecido pelos profissionais é um resultado esperado uma vez que esta pesquisa foi desenvolvida em uma instituição que possui um histórico de atendimento às gravidezes de fetos anencéfalos antes mesmo da legislação vigente. Isto é, além de habituados, os profissionais são qualificados para este cuidado, cuidado que deve estar presente nos demais espaços de cuidado à saúde das mulheres, pois diante da condição de gestar um bebê com malformação, a mulher necessita de uma atenção especial por parte dos profissionais de saúde, sendo acolhida e respeitada ${ }^{16}$. Este papel deve ser assumido pelos profissionais de saúde em todos os momentos da assistência, a começar pelo pré-natal ${ }^{15}$.
A interrupção da gestação em si pode ser classificada como um dilema nestes casos, onde comparecem questões variadas desde a escolha decidida, a não escolha decidida e a do âmbito das dúvidas. Esta última revelou desfechos diversos, desde complicações com sua saúde materna, questões judiciais e religiosas.

Nos casos das participantes E1, E3 e E8 estava-se diante de mulheres decididas a interromper a gestação, com escolhas bem situadas. Dentre seus motivos aponta-se: o desejo de findar com aquela gestação, de uma vez por todas, abreviando o tempo para poder tentar engravidar novamente (E1); e o fato de uma delas, uma vez sabendo que sua gestação atual não lhe daria um filho saudável, não quis "ficar presa” (E3) e priorizou voltar logo para casa e para o cuidado com seus três filhos.

Das 12 mulheres, apenas duas não quiseram interromper e conseguiram manter suas escolhas decididas até o fim (E5 e E7), seus bebês nasceram através de uma cesariana a termo. Para E5 a decisão de não interromper teve íntima relação com aquilo que relatou como falta de coragem relacionada aos sentidos atribuídos ao amor materno. No caso de E7, seu desejo era de dar um nome ao bebê e após nascer, que este pudesse ser enterrado junto da sua família.

Muitas mulheres conseguem encontrar sentido no fato de prosseguirem com a gestação, mesmo diante da inviabilidade do feto e devem ser respeitadas na sua vontade de continuarem grávidas $^{8}$. Para algumas há a necessidade de dar um nome e de enterrar ${ }^{24}$.

Quatro mulheres interromperam suas gestações por motivos relacionados com sua saúde (E2, E4, E10 e E12). No caso da E2 e E10, estas não demoraram na decisão de interromper, devido às complicações sentidas. Em contrapartida, a E12 decidiu pela interrupção somente no terceiro trimestre, quando as complicações começaram a comprometer a qualidade de vida do casal:

eu estava com arritmia direto e outras complicações - E10.

Apesar da presença de complicações na saúde, a decisão de interromper no caso da E4 se mostrou complexa, já que ela não queria, de fato, interromper a gestação, pela crença de que a mãe não deve interferir no tempo de vida fetal ${ }^{24}$ :

eu não conseguia aceitar o fato que eu tinha que interromper, eu queria deixar correr natural $-\mathrm{E} 4$.

Gestações de fetos anencéfalos estão relacionadas a complicações obstétricas diversas, eis um dos pontos levantados pela literatura a favor da 
interrupção da gestação. Dentre algumas complicações estão: doenças hipertensivas; complicações no momento do parto; insuficiência renal e cardíaca; descolamento prematuro da placenta; ruptura prematura das membranas; e infecção são identificadas nesses casos. Mais do que somente as intercorrências clínico-obstétricas, é preciso valorizar as consequências psicológicas de uma gestação de feto anencéfalo ${ }^{8,24}$. Tanto as complicações físicas quanto as de ordem emocional foram fatores que influenciaram nas decisões das mulheres deste estudo.

É interessante observar as narrativas de E6, E9 e E11, mulheres que, a princípio, desejaram interromper, mas que tiveram trajetórias que envolveram dificuldades na justiça, desistência da interrupção e interrupção em idade gestacional avançada. Assim, cumpre aqui situar pontos nevrálgicos que atravessaram suas decisões iniciais. Como abordado anteriormente, quatro mulheres tiveram que judicializar sua interrupção, dentre elas estavam E6 e E9. De início, as duas queriam interromper, tanto que recorreram a justiça, mas com o passar do tempo mudaram de ideia por diferentes motivos.

O caso da depoente E6 chamou a atenção devido à peregrinação sofrida, em busca da autorização para interromper a gestação, o que mais tarde resultou na divulgação deste caso na mídia. Inclusive, esse foi um dos fatores que auxiliaram na promulgação da súmula da interrupção de gestações de fetos anencéfalos. Esta mulher enfrentou a constrangedora negação do seu pedido por três vezes, fato frequente no Brasil, antes da promulgação da súmula ${ }^{8}$ :

foi muito difícil, todo dia eu ia [...] só levava não e não [...] ele (o desembargador) achou um absurdo [...] foi e jogou pra mídia [...] com esse depoimento do caso da minha neném [...] passou a liberar - E6.

Após tanto tempo de negativas, ela já havia desistido da interrupção. Por fim, aos sete meses de gestação chegou a decisão favorável e a depoente resolveu interromper a gestação por cesariana.

No caso de E9, ela entrou em trabalho de parto aos seis meses e, naturalmente, a gestação foi interrompida. Ocorre que ela, neste percurso, foi intimada judicialmente para interromper, mas foi algo que como ela mesma disse "deixou para lá":

eu entrei pra tentar fazer o aborto, mas no fundo eu não queria tirar - E9.

Para E11 a mudança de ideia se deu por motivos religiosos, em seu caso o bebê acabou vindo a óbito aos seis meses e o parto foi induzido. A literatura mostra que gestar um feto anencéfalo está relacionado com trabalho de parto prematuro e morte intraútero ${ }^{1,4,24}$ e assim foi no caso destas mulheres.

A depoente E2 desejou interromper, acionou a justiça e, de fato, concretizou a interrupção tanto pelo feto ser anencéfalo quanto por complicações em sua saúde. Entretanto, é um caso que revela exemplarmente a angústia vivida por algumas mulheres diante da situação de interromper ou não a gestação, onde escolhas são postas em contraditório. Para E2, os motivos também estavam relacionados aos seus valores religiosos. Ela afirmou de maneira veemente que era "contra o aborto", mesmo tendo optado pela interrupção da gestação. No contradito entre interromper ou não a gestação, optou pela primeira opção. Sua assertiva enfática foi uma maneira de assumir um mea-culpa:

quando eu fui pegar o alvará, eu me senti muito mal no tribunal, eu num lugar criminal, uma bandida igual um bandido - E2.

Neste caso, a ambiguidade de sentimentos foi notável e revelada em um conflito interior entre interromper ou não a gestação, levando-a a repensar conceitos condenatórios daquilo que ela intitulava como prática abortiva. Notam-se questões de foro íntimo geradoras de inconformidades, entre elas, a culpabilização de si mesma, a sensação de estar cometendo um crime e a decisão de 'esconder o cometido' perante os amigos. Com sentimentos de culpa, as mulheres podem vivenciar a interrupção como uma marca de caráter e no sentido de não serem estigmatizadas pelos amigos e pela sociedade, há uma necessidade de silenciar essa prática ${ }^{25}$. A religião é um dos fatores referidos pelas gestantes para não dar fim a gestação ${ }^{8}$.

Se o espaço relacional do pré-natal foi evidenciado enquanto um sítio de cuidado de qualidade, os processos que envolveram a internação hospitalar foram diferentes. O cuidado humanístico dos profissionais manteve-se presente, mas as dificuldades encontradas situavam-se nos aspectos subjetivos das mulheres relacionados à aproximação do momento do parto e de aspectos objetivos relacionados à infraestrutura da maternidade.

Internar-se para parir um feto inviável é estar diante de uma vivência dolorosa. Sentimentos diversos envolveram as mulheres por ocasião das suas admissões hospitalares: nervosismo, desespero, tristeza, dor e sofrimento intenso. E2 foi um caso extremo, pois teve ideal suicida devido à experiência de passar pelo trabalho de parto e não conseguir levar o bebê para casa: 
fiquei muito depressiva, fiquei muito doente [...] coisas que eu nunca pensei na minha cabeça, de me jogar em uma janela, eu tive - E2.

$\mathrm{Na}$ aproximação do desfecho não desejado, as mulheres referiram que o momento do parto com a visualização do bebê foi um dos piores momentos vividos. Nem todas as mulheres quiseram ver seus filhos, quatro delas, por acreditarem que o fato de entrar em contato e ver as deformidades iria dificultar o processo do luto ${ }^{6}$ :

não quis ver, não quis saber o sexo, não quis saber nada-E2.

$\mathrm{O}$ restante das entrevistadas fez questão de ver o bebê logo após o parto, tanto pela curiosidade de visualizar as deformidades, como para se despedir. Deve-se considerar que elas já estavam lidando com um luto ainda não palpável, de um bebê intraútero, a vontade de despedida é o início da concretização do luto a partir do real visualizado:

eu quis [...] dei tchau pra ele, eu, sabe, eu quis me despedir dele - E4.

O parto e o nascimento representam momentos de confronto entre a, ainda, esperança de ter ocorrido um erro no diagnóstico de malformação e as reais condições do recém-nascido, além de ser o primeiro encontro direto com o bebê. Esse momento é angustiante e marcado pela expressão do luto refletido na ausência de um bebê saudável ${ }^{15}$. Algumas mães necessitam ver o feto com todos os problemas, para que consigam crer plenamente, e a partir de uma realidade visível, no diagnóstico da malformação, para estabelecer um sentido psíquico para essa vivência ${ }^{6}$. Cabe a equipe que presta os cuidados acatar a escolha da mulher, em respeito ao momento vivido e proporcionar o que for necessário para que esta mulher possa experienciar este encontro com o bebê da maneira menos traumática possível.

Uma vez dados por encerrados o parto e a (não) despedida do bebê morto, essas mulheres passaram para o período em que foram encaminhadas, na instituição, para os setores de internação pós-parto. Existe um marcador objetivo que pode facilitar ou dificultar a vivência deste momento - o local onde esta mulher passou por seu período puerperal na instituição.

Isso ocorre, pois geralmente elas são encaminhadas a uma enfermaria chamada Alojamento Conjunto. O problema não é o local propriamente dito, mas por ser um espaço compartilhado com mulheres que estão acompanhadas de bebês. Para uma mulher que perdeu seu filho estar alocada no mesmo espaço com mães de bebês, em geral, saudáveis, é um ato violento. Isso não ocor- re por insensibilidade dos profissionais, mas, em geral, por uma ausência de um espaço restrito a estas mulheres e/ou, até mesmo, por hiperlotação das maternidades. Ainda que sejam bem tratadas e cuidadas, o local será sempre um deflagrador de memórias negativas, para grande maioria das mulheres.

O próprio conceito de 'maternidade' enquanto ambiente hospitalar encerra a ideia de que ali é um lugar onde se encontram as mães e seus bebês. E, de fato, é assim que ocorre. Rotinas e situações das mais diversas preenchem este espaço de sentidos: banhos, cuidados com o coto umbilical, amamentação, troca de fraldas, choro dos bebês etc. Ou seja, não são espaços para mulheres que perderam seu filho, não propiciando a vivência do luto. Ao contrário, potencializa questões do âmbito emocional trazendo fragilidades incomensuráveis. Os relatos das participantes apontaram para o desejo de experimentar colocar os bebês no colo e, desta forma, retornaram ao imaginário de poder sair com ele nos braços na alta hospitalar.

Dividir o espaço com outras mulheres e seus filhos coloca as que vivenciaram a perda em contato direto com tudo o que o seu filho representava deixando evidente a falta, a sensação do não ganhar ${ }^{18}$. A internação proporciona contato com gestações que terminaram em sucesso, o que provoca sentimentos mais intensos de fracasso, mais pela incapacidade sentida no gestar e pela ausência do filho imaginado e perdido, do que propriamente pela interrupção $0^{6,8}$.

O depoimento de E6 é capaz de mostrar a importância de não estar internada no mesmo espaço, coabitando com mães e bebês, naquele período de tempo. Ela relatou que a equipe teve o cuidado de deixá-la em uma enfermaria de gestantes após o parto, na tentativa de minimizar a dor da perda:

quando eu ganhei [...] me botaram junto com as outras que iam ganhar, pra não ficar junto das que já tiveram neném - E6.

É preciso valorizar o preparo e a sensibilização dos profissionais de saúde que atuam diretamente com as mulheres enlutadas como, por exemplo, na escolha da enfermaria que a mulher será alocada após o parto ${ }^{18}$. Devem-se considerar, evidentemente, as condições, infraestrutura e lotação das enfermarias. Mas, se possível, não se deve colocar mulheres que sofrem perda em enfermarias compartilhadas com mães e bebês.

Diante disso, o cuidado humanizado, direito da mulher garantido pelas diretrizes do Sistema Único de Saúde (SUS), é fundamental na elabo- 
ração do luto vivenciado pelos pais desde o momento do diagnóstico de malformação, passando pelo momento da internação e após a alta ${ }^{16}$. Desta forma, cabe aos profissionais de saúde ofertar uma assistência qualificada e o suporte emocional adequado para promover o enfrentamento dessa situação ${ }^{18}$.

\section{Considerações finais}

Conhecer as narrativas de mulheres que vivenciaram gestação de fetos anencéfalos nos impulsiona a pensar sobre o despreparo dos serviços - enquanto instituições e enquanto pessoas que o concretizam - em lidar com o processo de decisão vivenciado por mulheres, seus parceiros e suas fa- mílias. Em cada narrativa de vida, somos defrontados pela escassez de literatura que dialogue com as (novas) questões analisadas nos depoimentos.

Os sentimentos vivenciados pelas mulheres durante toda a trajetória (tornados notórios durante as entrevistas), o problema da interrupção da gestação de fetos anencéfalos e as dificuldades enfrentadas durante todo o percurso são pontos cruciais que o estudo identificou. No entanto, as fragilidades que precisam ser geridas para a construção de um SUS pleno, visando melhorias à atual (des)organização do cuidado a estas mulheres, e a garantia de seus direitos reprodutivos, muitas vezes desrespeitados, são reflexões necessárias para avançarmos no campo da assistência às mulheres que enfrentam gravidezes de fetos inviáveis.

\section{Colaboradores}

Todos os quatro autores participaram ativamente da concepção, da discussão dos resultados, da revisão e aprovação da versão final do estudo. 


\section{Referências}

1. Massud M. Anencefalia numa perspectiva ética. Rev Bras Saude Materno Infantil 2010; 10(Supl. 2):S263-S270.

2. Diniz D, Vélez ACG. Aborto na Suprema Corte: o caso da anencefalia no Brasil. Estudos Feministas 2008; 16(2):440.

3. Diniz D, Penalva J, Fagúndes A, Rosas C. A magnitude do aborto por anencefalia: um estudo com médicos. Cien Saude Colet 2009; 14(1):1619-1624.

4. Nunes HHM. A enfermagem e o nascimento de um bebê com anencefalia: contribuição para mães e profissionais de saúde [tese]. Rio de Janeiro: Escola de Enfermagem Anna Nery da Universidade Federal do Rio de Janeiro; 2012.

5. Brasil. Ministério da Saúde (MS). Secretaria de Atenção à Saúde. Departamento de Ações Programáticas Estratégicas. Atenção às Mulheres com Gestação de Anencéfalos. Norma Técnica. Série Direitos Sexuais e Direitos Reprodutivos - Caderno $n^{\circ} 11$. Brasília: MS; 2014.

6. Benute GRG, Nomura RMY, De Lucia MCS, Zugaib M. Interrupção da gestação após o diagnóstico de malformação fetal letal: aspectos emocionais. Rev Bras Ginecol Obstet 2006; 28(1):10-17.

7. Foganholi LPM. Aborto de feto anencéfalo é discriminalizado pelo Supremo Tribunal Federal. ETIC - Encontro de Iniciação Científica 2013; 9(9):1-7.

8. Silva MH, Rodrigues MFS, Amaral WN. Aspectos médicos e psicológicos de grávidas portadoras de feto anencefálico. Femina 2011; 39(10):493-498.

9. Bertaux D. Narrativas de vida: a pesquisa e seus métodos. São Paulo/Natal: EDUFRN/Paulus; 2010.

10. Brasil. Conselho Nacional de Saúde (CNS). Resolução $n^{\circ} 466$, de 12 de dezembro de 2012. Aprova diretrizes e normas regulamentadoras de pesquisas envolvendo seres humanos. Diário Oficial da União 2013; 13 jun.

11. Fontanella BJB, Luchesi BM, Saidel MGB, Ricas J, Turato ER, Melo DG. Amostragem em pesquisas qualitativas: proposta de procedimentos para constatar saturação teórica. Cad Saude Publica 2011; 27(2):389-394.

12. Brasil. Ministério da Saúde (MS). Secretaria de Vigilância em Saúde. Secretaria de Atenção à Saúde. $M a$ nual de Vigilância do Óbito Infantil e Fetal e do Comitê de Prevenção do Óbito Infantil e Fetal. 2a ed. Brasília: MS; 2009. (Série A. Normas e Manuais Técnicos).

13. Instituto Brasileiro de Geografia e Estatística (IBGE). Censo Brasileiro de 2010 [página na Internet]. [acessado 2018 Maio 27]. Disponível em: http://mapasinterativos.ibge.gov.br/atlas_ge/brasillpor1.html

14. Leite RRQ, Frota MMC. O desejo de ser mãe e a barreira da infertilidade: uma compreensão fenomenológica. Rev Abordagem Gestalt 2014; 20(2):151-160.
15. Roecker S, Mai LD, Baggio SC, Mazzola JC, Marcon SS. A vivência de mães de bebês com malformação. Esc Anna Nery 2012; 16(1):17-26.

16. Cunha ACB, Pereira Junior JP, Caldeira CLV, Carneiro VMSP. Diagnóstico de malformações congênitas: impactos sobre a saúde mental de gestantes. Estudos de Psicologia 2016; 33(4):601-611.

17. Marin A, Piccinini CA. Famílias uniparentais: a mãe solteira na literatura. Psico 2009; 40(4):422-429.

18. Lemos LFS, Cunha ACB. Concepções sobre morte e luto: experiência feminina sobre a perda gestacional. Psico Cien Profissão 2015; 35(4):1120-1138.

19. Gomes AG, Piccinini CA. Impressões e sentimentos das gestantes sobre a ultra-sonografia e suas implicações para a relação materno-fetal no contexto de anormalidade fetal. Psico 2007; 38(1):67-76.

20. Carvalho QCM, Cardoso MVLML, Oliveira MMC, Lúcio IML. Malformação congênita: significado da experiência para os pais. Cien Cuidado Saude 2006; 5(3):389-397.

21. Santos SR, Dias IMAV, Salimena AMO, Bara VMF. A vivência dos pais de uma criança com malformações congênitas. Rev Min Enferm 2011; 15(4):491-497.

22. Vasconcelos L, Petean EBL. O impacto da malformação fetal: indicadores afetivos e estratégias de enfrentamento das gestantes. Psico Saude Doenças 2009; 10(1):69-82.

23. Penna MLF. Anencefalia e morte cerebral (neurológica). Physis 2005; 15(1):95-106

24. Sala DCP, Abrahão AR. Complicações obstétricas em gestações com feto portador de anomalia incompatível com a sobrevida neonatal. Acta Paul Enferm 2010; 23(5):614-618.

25. Adesse L, Jannotti CB, Silva KS, Fonseca VM. Aborto e estigma: uma análise da produção científica sobre a temática. Cien Saude Colet 2016; 21(12):3819-3832.

Artigo apresentado em 19/11/2017

Aprovado em 15/06/2018

Versão final apresentada em 17/06/2018 